\title{
Ignition of Isomers of Pentane: An Experimental and Kinetic Modeling Study
}

\author{
M. Ribaucour, R. Minetti, L.R. Sochet, H.J. Curran, W.J. \\ Pitz, C.K. Westbrook
}

This article was submitted to Twenty Eighth International Symposium on Combustion, Edinburgh, Scotland, July 30 - August 4,2000

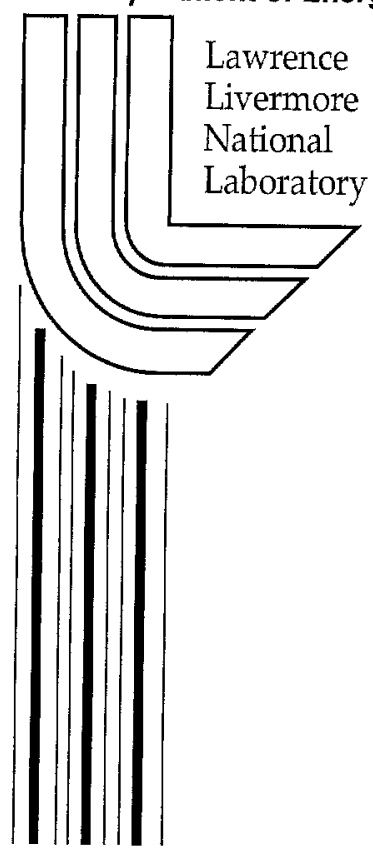

January 11, 2000 


\section{Introduction}

Hydrocarbon ignition is an important element in many practical combustion systems, including internal combustion engines, detonations, pulse combustors, and flame initiation. The rapid compression machine ( $R C M)$ is used frequently to study the kinetics of hydrocarbon autoignition [e.g., 1-7], since the reactive gas temperatures and time histories are similar to those seen in automotive engines during Diesel ignition and enḍ gas autoignition leading to engine knock in spark-ignition engines.

The RCM provides a rich environment for study of the theory of hydrocarbon oxidation, including degenerate chain branching, alkylperoxy radical isomerization and effects of thermal feedback [8]. The literature of hydrocarbon oxidation studies in the RCM has been summarized recently $[9,10]$, and many classes of fuels have been studied. Detailed kinetic modeling is another tool available to study hydrocarbon oxidation in the RCM $[4,11]$. The aim of the present work is to determine experimentally the influence of variations in fuel molecular structure on autoignition, and to use a kinetic model to understand the reasons for those variations. This study is unique in that while other studies have addressed variations in pressure and equivalence ratio on ignition [11], this work addresses effects of variations in fuel molecular structure for all of the isomers of a single fuel formula, pentane, in a RCM. The three isomers of pentane possess many of the structural elements that determine such autoignition characteristics as octane number and variability in cool flame production, so this study will benefit our efforts to describe these effects. 


\section{Experimental results}

The experimental facility developed at Lille enables rapid compression of a reactive mixture of hydrocarbon/oxygen/inert by a piston stroke. The overall compression ratio is 9.28 , and the time for compression in the present study is $60 \mathrm{~ms}$. The piston is locked at the end of its travel (top dead centre = TDC) so that the reacting mixture remains at constant volume until ignition occurs. Pressure-time data during compression and the postcompression, constant volume period are measured by a Kistler transducer and recorded at a sampling rate of $25 \mathrm{kHz}$. Light emission associated with the cool flame is measured by a photomultiplier fitted with a color blue filter. Full details of the apparatus and experimental procedures have been described previously $[12,13]$.

Pressure and temperature at TDC must be known as precisely as possible. Pressure is measured experimentally at the end of the pressure rise associated with the compression stroke. Temperature at TDC is not readily accessible by measurement and must be calculated from the pressure according to a suitable model. The assumption of an adiabatic compression is unrealistic in our case because at least two factors can alter the temperatures in the compressed gases. These factors include heat losses to the combustion chamber walls and heat release from chemical reactions during compression. In our experience, experimental pressures at TDC are usually lower than the theoretical pressures calculated with the adiabatic law, meaning that heat losses during compression are greater than reactive heat release during compression.

Therefore, temperatures at the end of compression are calculated from the pressure at TDC, the initial pressure and temperature, the compression ratio and the perfect gas law, taking into consideration the temperature-dependent specific heats of the reactants. Temperatures computed in this manner represent spatial averages 
because, due primarily to heat losses to the combustion chamber walls, different regions in the compressed gas have local temperatures that are higher and lower than the averaged temperature. Autoignition delay times computed from this average temperature can produce results that are either longer or even shorter than the experimentally determined values [11], as discussed below.

One must consider that the reaction mixture at TDC is not homogeneous but includes pockets of hotter gas that do not experience heat loss. Such hot spots have been observed by LIF of formaldehyde in the turbulent gas mixture of an optical motored engine [14]. The adiabatic core gas model [15] takes into account the inhomogeneity of the reacting mixture. The concept is based on the assumption of an adiabatic core zone, for which the temperature can be calculated with the adiabatic law using the measured pressure at TDC. In that concept the pressure is supposed homogeneous in the chamber, but not the temperature. The core-gas is surrounded by a boundary zone that cools down by heat transfer. With time, the core gas volume shrinks and finally vanishes when the reaction time becomes very long. Temperature at TDC has been measured in the centre of the rapid compression machine using laser Rayleigh scattering [16] and is in good agreement with the theoretical adiabatic core-gas temperature [17]. The computed core gas temperature matches the measured temperature reasonably well during $200 \mathrm{~ms}$ after TDC. Temperature measurements by thermocouple have shown that the core gas occupies about $80 \%$ of the chamber [18]. A reduced level of temperature inhomogeneities has been observed before ignition and can be explained by the negative temperature coefficient of the reaction rate through its feedback action on the heat release.

Delay times of the first (cool flame) and second stage ignition of n-pentane, isopentane, and neopentane have been deduced from the pressure and light emission 
traces. Each reactive mixture consisted of fuel/oxygen/diluent in the ratio 1/8/30.08; thus when the diluent is $\mathrm{N}_{2}$, the mixture is stoichiometric pentane/air. In order to reach compression temperatures over the range $640-900 \mathrm{~K}$, part or all of nitrogen was replaced by argon or carbon dioxide. For each fuel, twelve stoichiometric mixtures have been studied. At least three identical experiments were conducted on each mixture with initial pressures $p_{0}$ of 300 and 400 torrs. Experimental results are presented as ignition delay times versus core gas temperature at TDC in Fig. 1-3. The autoignition behavior may be characterized by the following quantities: the lowest temperature at which autoignition takes place $\left(\mathrm{T}_{1}\right)$, the extent of the negative temperature coefficient (NTC) zone $\left(\mathrm{T}_{\min }, \mathrm{T}_{\max }\right)$, the minimum and the maximum ignition delay times within that zone $\left(t_{\min }, t_{\text {max }}\right)$, and the extent of the cool flame (CF) zone $\left(\mathrm{T}_{\text {CFmin }}, \mathrm{T}_{\text {CFmax }}\right)$. These values are reported for the three hydrocarbons in Table I.

With its high research octane number ( $R O N=92.3)$, isopentane is the least reactive among the three isomers. The ignition delay times in the NTC zone are the longest (Table I). Ignition was not observed below $690 \mathrm{~K}$, a clear negative temperature coefficient of the reaction rate was seen from about $730 \mathrm{~K}$ to $820 \mathrm{~K}$ (Fig. 1) and the temperature range of $700-755 \mathrm{~K}$ in which cool flames were observed is narrow. $\mathrm{N}$-Pentane (Fig. 3) is the most reactive isomer. Its low octane number $(\mathrm{RON}=$ 61.7 ) is consistent with a low ignition limit $T_{1}$ of $650 \mathrm{~K}$ and the shortest ignition delay times in the NTC zone. The NTC and the cool flame zone extend over wide ranges of temperature: $755-845 \mathrm{~K}$ and $665-845 \mathrm{~K}$ respectively at 400 torrs.

The ignition limit for neopentane is about $670 \mathrm{~K}$, intermediate between the values for $\mathrm{n}$-pentane and isopentane, consistent with its octane number $(\mathrm{RON}=85.5)$. However some peculiarities have to be underlined. The ignition delay decreases slowly 
with temperature after about $770 \mathrm{~K}$ at both initial pressures (Fig. 2), but a negative temperature dependence is not evident. Experiments carried out at 200 torrs (not presented here) showed a weak negative temperature coefficient of reaction rate between 770 and $850 \mathrm{~K}$. In a high pressure flow reactor study of neopentane oxidation, Wang et al. [19] observed NTC behavior but commented that it was much less pronounced than n-pentane under comparable conditions.

Another interesting feature of neopentane autoignition is the persistence of cool flame activity over the entire range of investigated temperatures. Moreover, for compression temperatures above $770 \mathrm{~K}$, the cool flame occurs before the end of the compression stroke. The measured pressure at TDC is therefore influenced by heat release from the cool flame and results in a calculated core gas temperature about $20 \mathrm{~K}$ greater for these higher temperature cases for neopentane than for the other isomers which did not show cool flame behavior during compression. The kinetic modeling discussion below will provide an explanation for the early reactivity of neopentane.

\section{MODELING OF IGNITION DELAY TIMES}

The chemical kinetic reaction mechanisms used for these simulations are based on a long history of mechanism development. Recent modeling studies of n-pentane [4,11,20], neopentane (2,2-dimethyl propane) [19-21], and iso-pentane (2-methyl butane) [20]. These mechanisms are continually being refined, but the three mechanisms used here are at the same level and detail as that reported [19] for neopentane. For the current study, the three mechanisms were combined into a single, larger mechanism which is too large to include here but is available from the authors, in either paper or electronic form (pitz1@1lnl.gov or westbrook1@1lnl.gov). No mechanism modifications 
were made to alter the computed results or their level of agreement with experimental data.

The numerical model followed the reactant evolution through the entire compression stroke, as well as over the constant volume period. In order to include the effects of heat losses to the chamber walls, a non-reactive experiment was carried out by replacing oxygen with nitrogen. A time-dependent, distributed heat transfer coefficient was then determined to match the computed and experimental pressure history, as shown in Figure 4. That heat transfer treatment was then included in all of the subsequent model calculations, with the following exception. During compression, there is considerable turbulence and mixing of the reactants in the combustion chamber, so that the heat losses can be presumed distributed rather uniformly throughout the mixture. Once the piston stops, we assume that the heat losses come from those gases near the chamber wall, maintaining an adiabatic core that retains heat for a longer period of time. Therefore we included heat losses during the compression stroke and neglected them during the constant volume period. This assumption should be reasonably valid except for long times after the end of compression, when heat transfer from the core will render it no longer adiabatic.

In another series of model computations, the pressure measured at TDC and the resulting core gas temperature were used as initial conditions, without simulating the compression stroke. The results shown as dashed lines in Figs. 1-3 are not very different from those where simulations of reactions during the compression stroke were included. 


\section{RESULTS}

The computed results are shown as the curves in Figs. 1-3. As done above for the experimenal results, the figures show both the time of onset of the first stage ignition and the time of the final ignition. The computed results obtained when the compression period was not modeled are shown as dashed curves.

Overall agreement between computed and experimental results is generally very good for both the total ignition delay and the time of the first stage ignition. Only for the lower pressure experiments with iso-pentane are the differences quantitatively significant, with the computations indicating ignition at about $60 \mathrm{~ms}$ while the experiments showed ignition at about $100 \mathrm{~ms}$. At these very long experimental ignition delay times, it is likely that the assumption in the model of adiabatic conditions is breaking down. To test this hypothesis, the computed constant-volume portions of these histories were repeated, introducing heat loss with the same rate as that used during the compression stroke. With the same heat loss rate, these computer simulations all failed to ignite at any time following the end of compression. Even with smaller rates of heat transfer, these mixtures either completely failed to ignite, or ignited at very long elapsed times. Thus it is apparent that the differences between computed and experimental ignition delay times for iso-pentane are likely due to uncertainties in the heat transfer treatment in the model and the fact that the experimental problem is not thermally homogeneous. In all the other cases for the other isomers, the ignition was so rapid and vigorous in both the model and experiment that it was insensitive to heat losses.

The relative behavior of the three isomers of pentane is illustrated in Figure 5, showing the computed temperatures for each isomer at a compression temperature of 757K and initial pressure of 400 torrs. The compression histories, including 
temperatures, of the three cases are virtually identical, but the constant volume ignitions are quite different. All three show a distinct first stage ignition, but the time delays for that first ignition are very short $(2.4 \mathrm{~ms})$ for $\mathrm{n}$-pentane, longer for neopentane $(6 \mathrm{~ms})$ and much longer for iso-pentane $(7.5 \mathrm{~ms})$. The amount of temperature increase $(\Delta \mathrm{T}=$ $163 \mathrm{~K}, 106 \mathrm{~K}, 70 \mathrm{~K}$, respectively) and fuel consumption ( $\Delta$ fuel $=41 \%, 21 \%, 20 \%$

respectively) during the first stage ignition for n-pentane, neopentane, and iso-pentane are much different, as is the duration of the first stage ignition $(0.7 \mathrm{~ms}, 3 \mathrm{~ms}, 2.6 \mathrm{~ms}$, respectively). The onset of the second stage of igntion occurs in the same order as one would predict from the relative octane ratings for these fuels.

For each of the three pentane isomers, low temperature oxidation under these conditions takes place via an alkylperoxy radical isomerization pathway. The major features of these reactions have been discussed many times [e.g., 22,23], and only the essential elements will be included here. At the relatively low temperatures following compression, the main reactions for all three isomers in these stoichiometric mixtures are $\mathrm{H}$ atom abstraction from the fuel, nearly all of it by reaction with $\mathrm{OH}$ radicals

$$
\mathrm{C}_{5} \mathrm{H}_{12}+\mathrm{OH}=\mathrm{C}_{5} \mathrm{H}_{11}+\mathrm{H}_{2}
$$

$\mathrm{H}$ atom abstraction by $\mathrm{OH}$ varies relatively weakly with the type of $\mathrm{C}-\mathrm{H}$ bond being broken with primary $\mathrm{C}-\mathrm{H}$ bonds being somewhat stronger than secondary $\mathrm{C}-\mathrm{H}$ bonds and tertiary bonds being weakest, but $\mathrm{H}$ atom abstraction will still produces each type of alkyl radical possible for the each isomer. At the temperatures at the end of compression, the processes leading to the first stage ignition begin through the pentyl radicals reacting by addition to molecular oxygen:

$$
\mathrm{C}_{5} \mathrm{H}_{11}+\mathrm{O}_{2}=\mathrm{C}_{5} \mathrm{H}_{12} \mathrm{O}_{2}
$$


These pentylperoxy radicals then isomerize via internal abstraction of $\mathrm{H}$ atoms. The rates of these isomerization reactions depend primarily on two major elements, the type of $\mathrm{C}-\mathrm{H}$ bond being broken and the number of atoms in the transition state ring through which the $\mathrm{H}$ atom is abstracted. The activation energy $\mathrm{E}_{\mathrm{iso}}$ for the isomerization can be written [23] as the sum of the ring strain energy $\mathrm{E}_{\mathrm{rS}^{\prime}}$ the bond energy for the bond being broken $\mathrm{E}_{\mathrm{b} o n d}$, and the endothermicity $\Delta \mathrm{E}$ of the overall reaction.

$$
\mathrm{E}_{\text {iso }}=\mathrm{E}_{\mathrm{rs}}+\mathrm{E}_{\mathrm{bond}}+\Delta \mathrm{E}
$$

The most reactive pentane isomer is n-pentane, with a structure of:

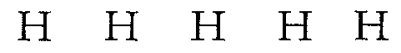

$$
\begin{aligned}
& \mathrm{H}-\mathrm{C}-\mathrm{C}-\mathrm{C}-\mathrm{C}-\mathrm{C}-\mathrm{H} \\
& \begin{array}{lllll}
\mathrm{H} & \mathrm{H} & \mathrm{H} & \mathrm{H} & \mathrm{H}
\end{array}
\end{aligned}
$$

This molecule can be rewritten to indicate different, logically distinct $\mathrm{H}$ atoms:

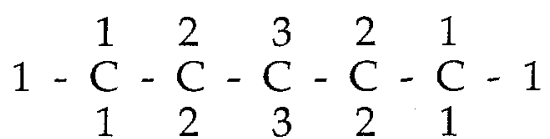

Isomerization of pentylperoxy radicals in this fuel is facilitated by the ready availability of secondary site $\mathrm{H}$ atoms at sites (sites 2 and 3 in the model above) that involve 6membered transition state rings. This is true because $\mathrm{E}_{\mathrm{rs}}$ is a minimum when a 6membered transition state ring is involved, while $\mathrm{E}_{\text {bond }}$ is smaller for breaking a secondary bond than a primary bond. Model computations show that 
the major products of 1-pentylperoxy and 2-pentylperoxy radical isomerizations are :

$$
\begin{aligned}
& \mathrm{H} \\
& \mathrm{O} \\
& \mathrm{O} \mathrm{H} \cdot \mathrm{H} \mathrm{H} \\
& \mathrm{H}-\mathrm{C}-\mathrm{C}-\mathrm{C}-\mathrm{C}-\mathrm{C}-\mathrm{H} \\
& \begin{array}{lllll}
\mathrm{H} & \mathrm{H} & \mathrm{H} & \mathrm{H} & \mathrm{H}
\end{array}
\end{aligned}
$$

and

$$
\begin{aligned}
& \mathrm{H} \\
& \text { O } \\
& \begin{array}{cccccc}
\mathrm{H} & \mathrm{O} & \mathrm{H} & . & \mathrm{H} \\
\mathrm{H}-\mathrm{C} & -\mathrm{C} & -\mathrm{C} & -\mathrm{C} & -\mathrm{C} & -\mathrm{H} \\
\mathrm{H} & \mathrm{H} & \mathrm{H} & \mathrm{H} & \mathrm{H}
\end{array}
\end{aligned}
$$

both of which are favored because they involve 6-membered transition state rings and weakly bound secondary site $\mathrm{H}$ atoms (i.e., $(1,5 \mathrm{~s})$ reactions). Note that the rate of the comparable isomerization of 3-pentylperoxy radicals is relatively inhibited because, although a 6-membered transition state ring structure is attainable, it involves internal abstraction of an $\mathrm{H}$ atom from a primary $(1,5 \mathrm{p})$ process, rather than a secondary site. Subsequent reaction steps leading to chain branching and rapid reaction involve addition of another $\mathrm{O}_{2}$ molecule to the $\mathrm{QOOH}$ radical site in the above species, followed by a series of further internal $\mathrm{H}$ atom abstractions, following the same principles for activation energy barriers noted for alkylperoxy radical internal $\mathrm{H}$ atom abstractions. These final species eventually decompose to produce 3 or more radical species, providing chain branching.

Neopentane is unique in that it consists entirely of tightly bound primary 
$\mathrm{C}-\mathrm{H}$ bonds :

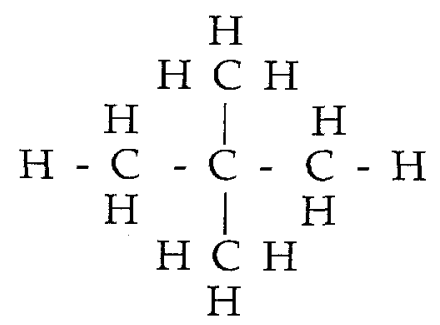

Following $\mathrm{H}$ atom abstraction and addition of molecular oxygen, there are $9 \mathrm{H}$ atoms available for internal abstraction, each of which is relatively strongly bound at primary sites but have the advantage of low activation barrier 6-membered transition state ring locations. That is, the pentylperoxy radical has the structure :

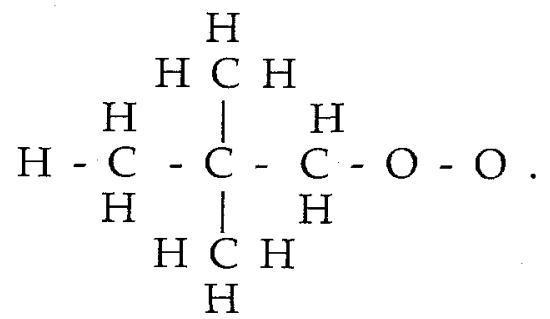

Although the energy barrier to this $(1,5 \mathrm{p}) \mathrm{H}$ atom abstraction is $1.75 \mathrm{kcal} / \mathrm{mole}$ higher than the $(1,5 \mathrm{~s})$ transfers in $\mathrm{n}$-pentane, there are $9 \mathrm{H}$ atoms available, which facilitates this reaction step and allows the reaction sequence to proceed relatively rapidly. The absence of an NTC regime for neopentane is due in large measure to the fact that there is no conjugate alkene that can be formed by neopentane, due to its highly symmetric and completely primary $\mathrm{C}-\mathrm{H}$ structure.

Iso-pentane has the structure:

$$
\begin{aligned}
& \mathrm{H} \\
& \mathrm{HCH} \\
& \begin{array}{l|ll}
\mathrm{H} & \mathrm{H} & \mathrm{H}
\end{array} \\
& \mathrm{H}-\mathrm{C}-\mathrm{C}-\mathrm{C}-\mathrm{C}-\mathrm{H} \\
& \begin{array}{llll}
\mathrm{H} & \mathrm{H} & \mathrm{H} & \mathrm{H}
\end{array}
\end{aligned}
$$


The initial most easily abstracted $\mathrm{H}$ atom is that at the tertiary site, with the formation of a corresponding $\mathrm{C}_{5} \mathrm{H}_{11} \mathrm{O}_{2}$ radical. However, subsequent internal $\mathrm{H}$ atom abstraction is inhibited relative to neopentane and n-pentane. In neopentane, there are $9 \mathrm{H}$ atoms at primary sites with 6-membered transition state rings, while in iso-pentane, there are only $3(1,5 \mathrm{p}) \mathrm{H}$ atoms available. All other internal $\mathrm{H}$ atom abstraction reactions in isopentane are more inhibited because they involve 5 membered transition state rings, either $(1,4 \mathrm{p})$ or $(1,4 \mathrm{~s})$ steps, or the initial $\mathrm{H}$ atom abstraction is inhibited because it involved the more strongly bound primary $\mathrm{C}-\mathrm{H}$ bonds. Therefore, the overall rate of chain branching in iso-pentane is lower than that for neopentane by at least a factor of three, so its ignition is considerably slower than that of neopentane, as seen in both the computed simulations and the experiments.

The first stage ignition ends when the temperature has increased enough to reverse the addition reactions of molecular oxygen to alkyl and hydroperoxyalkyl radicals. The smaller number of alkylperoxy radicals that are formed also decompose via lower activation energy, chain propagation pathways to produce olefin $+\mathrm{OH}$ and epoxide $+\mathrm{HO}_{2}$ species. This effectively shuts off the chain branching reaction pathways, and reaction remains slow until higher temperatures activate new, alternative reaction pathways.

For all three isomers of pentane, the second stage or hot ignition has exactly the same kinetic source. As seen in Figure 5, all three fuels ignite at approximately the same temperature of about $950 \mathrm{~K}$. For the pressures of this study, this is the temperature at which hydrogen peroxide $\left(\mathrm{H}_{2} \mathrm{O}_{2}\right)$ decomposes at a significant rate. Low temperature reactions produce an increasing amount of $\mathrm{H}_{2} \mathrm{O}_{2}$ that is stable until the temperature 
reaches a level where it decomposes rapidly; since this step involves a reaction that is part of the $\mathrm{H}_{2} / \mathrm{O}_{2}$ reaction submechanism, this ignition temperature is independent of the specific hydrocarbon fuel being studied, in agreement with the experimental observations in this study. Past kinetic modeling studies have demonstrated that this same decomposition reaction is responsible for the onset of knock in spark-ignition engines [20,24], ignition in Diesel engines [25], and ignition under Homogeneous Charge Compression Ignition (HCCI) conditions [26].

The kinetic modeling analysis shows that the three isomers of pentane ignite at different times primarily because their first stage ignition properties are very different and cause them to arrive at differing times at conditions where the hot ignition takes place. The most reactive isomer, $\mathrm{n}$-pentane, has the most vigorous first stage ignition and has the greatest amount of temperature increase associated with it, while neopentane has a slower first stage ignition with lesser amounts of temperature increase. Iso-pentane has the slowest first stage ignition and the least heat release and temperature rise. These differences in first stage ignition properties are attributable completely to differences in their molecular structure and the types of $\mathrm{C}-\mathrm{H}$ bonds in these molecules. Even though the rates of reaction of the three isomers are relatively similar following the end of the first stage ignition, $n$-pentane is much closer to the onset of the hot ignition determined by $\mathrm{H}_{2} \mathrm{O}_{2}$ decomposition.

There are a number of implications of this work for modeling analysis of practical combustion systems. It is clear that low temperature, alkylperoxy radical isomerization plays a major role in many ignition situations, including engine knock and Diesel ignition, where the combustion gases pass through exactly the same temperature ranges as in this study. In addition, the overall success of the kinetic model to reproduce 
both the major trends as well as the numerical detail of the experimental results indicates that the most important kinetic features of these problems are captured by the current family of reaction mechanisms, in particular the influences of fuel molecular size and structure. Finally, the value of the rapid compression machine to examine these issues has again been confirmed; in addition, this work has been able to examine the sensitivity of some RCM experiments to details in the heat transfer model and spatial inhomogeneities in temperature in the combustion chamber.

\section{CONCLUSIONS}

This study has examined the role that molecular structure plays in determining the low temperature reactivity and eventual ignition of a family of closely related hydrocarbon fuels, using both experimental results from a rapid compression machine and a chemical kinetic model. The kinetic model describes the experimental results very well, except for the one group of experiments in which thermal heat losses in the experiments are not properly reproduced by the model. The structural kinetic factors responsible for the observed variability of ignition with fuel structure have been described.

\section{ACKNOWLEDGMENTS}

This work was performed under the auspices of the U.S. Department of Energy by the University of California, Lawrence Livermore National Laboratory under Contract No. W-7405-Eng-48. 


\section{REFERENCES}

1. Griffiths, J.F., Halford-Maw, P.A., and Rose, D.J., Combust. Flame 95, 291 (1993).

2. Minetti, R., Ribaucour, M., Carlier, M., Fittschen, C., and Sochet, L.R., Combust. Flame 96, 201 (1994).

3. Park, P., and Keck, J.C., SAE Paper 900027, 1990.

4. Cox, A., Griffiths, J.F., Mohamed, C., Curran, H.J., Pitz, W.J., and Westbrook, C.K., Twenty-Sixth Symposium (International) on Combustion, The Combustion Institute, Pittsburgh, 1996, p. 2685.

5. Kirsch, L.J., and Quinn, C.P., Sixteenth Symposium (International) on Combustion, The Combustion Institute, Pittsburgh, p. 233 (1976).

6. Carlier, M., Corre, C., Minetti, R., Pauwels, J.-F., Ribaucour, M., and Sochet, L.-R., Twenty-Third Symposium (International) on Combustion, The Combustion Institute, Pittsburgh, p. 1753 (1991).

7. Minetti, R., Carlier, M., Ribaucour, M., Therssen, E., and Sochet, L.-R., TwentySixth Symposium (International) on Combustion, The Combustion Institute, Pittsburgh, p. 747 (1996).

8. Griffiths, J.F., and Scott, S.K., Prog. Energy Combust. Sci. 13, 161 (1987).

9. Griffiths, J.F., and Mohamed, C., Chapter 6 in Comprehensive Chemical Kinetics (G. Hancock, Ed.), Elsevier, Amsterdam (1999).

10. Griffiths, J.F., Prog. Energy Combust. Sci. 21, 25 (1995).

11. Westbrook, C. K., Curran, H. J., Pitz, W. J., Griffiths, J. F., Mohamed, C., and Wo, S. K. Twenty-Seventh Symposium (International) on Combustion, The Combustion Institute, Pittsburgh, pp. 371-378 (1998).

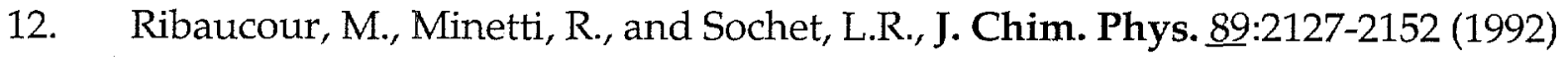


13. Minetti, R., Ribaucour, M., and Sochet, L.R., Combust. Sci. Technol. 113-114:179$192(1996)$

14. Buerle, B., Hoffmann, F., Behrendt, F., and Warnatz, J., Twenty-Fifth Symposium (International) on Combustion, The Combustion Institute, Pittsburgh, pp. 135$141,1994$.

15. Hu, H., Keck, J., SAE paper 87-2110, 1987

16. Desgroux, P., Gasnot, L., and Sochet, L.R., App1. Phys. B61:69-72 (1995)

17. Minetti, R., Ribaucour, M., Carlier, M., Fittschen, C. and and Sochet, L.R., Comb. Flame. $\underline{96}, 201-211$ (1994)

18. Desgroux, P., Minetti, R., and Sochet, L.R., Combust. Sci. Technol. 113-114:192303 (1996)

19. Wang, S., Miller, D. L., Cernansky, N. P., Curran, H. J., Pitz, W. J., and Westbrook, C. K., Comb. Flame 118, 415-430 (1999).

20. Curran, H. J., Gaffuri, P., Pitz, W. J., Westbrook, C. K., and Leppard, W. R., Twenty-Sixth Symposium (International) on Combustion, The Combustion Institute, Pittsburgh, pp. 2669-2677 (1996).

21. Curran, H. J., Pitz, W. J., Westbrook, C. K., Hisham, M. W. M., and Walker, R. W., Twenty-Sixth Symposium (International) on Combustion, The Combustion Institute, Pittsburgh, pp. 641-649 (1996).

22. Curran, H. J., Gaffuri, P., Pitz, W. J., and Westbrook, C. K., Combust. Flame 114, 149-177 (1998).

23. Pollard, R. T., Comprehensive Chemical Kinetics, Vol. 17 (C. H. Bamford and C. F. H. Tipper, Eds.), Elsevier, New York (1977).

24. Westbrook, C. K., Pitz, W. J., and Leppard, W. R., SAE Paper 912314, Society of Automotive Engineers (1991). 
25. Flynn. P. F., Durrett, R. P., Hunter, G. L., zur Loye, A. O., Akinyemi, O. C., Dec, J. E., and Westbrook, C. K., SAE Paper.1999-01-0509, Society of Automotive Engineers (1999)

26. Aceves, S. M., Flowers, D. L., Westbrook, C. K., Smith, J. R., Pitz, W. J., Dibble, R., Christensen, M., and Johansson, B., SAE Paper 2000-03-0327, Society of Automotive Engineers (2000) 


\section{LEGENDS}

Fig. 1 : Delay times of cool flame and total ignition for stoichiometric mixtures of isopentane/oxygen/inert at initial pressures of $400(a)$ and $300(b)$ torrs. Open (cool flame) and filled (total ignition) symbols : experiment, $\mathrm{T}=$ core gas temperature at TDC. Solid line: simulation including the compression phase; dashed line: simulation without the compression phase, $\mathrm{T}=$ core gas temperature at TDC.

Fig. 2 : Delay times of cool flame and total ignition for stoichiometric mixtures of neopentane/oxygen/inert at initial pressures of 400 (2a) and $300(2 b)$ torrs. Open (cool flame) and filled (total ignition) symbols : experiment, $\mathrm{T}=$ core gas temperature at TDC. Solid line: simulation including the compression phase, dashed line: simulation without the compression phase, $\mathrm{T}=$ core gas temperature at TDC.

Fig. 3 : Delay times of cool flame and total ignition for stoichiometric mixtures of n-pentane/oxygen/inert at initial pressures of $400(3 a)$ and $300(3 b)$ torrs. Open (cool flame) and filled (total ignition) symbols: experiment, $\mathrm{T}=$ core gas temperature at TDC. Solid line: simulation including the compression phase, dashed line: simulation without the compression phase, $\mathrm{T}=$ core gas temperature at TDC.

Dashed line : simulation without the compression phase, $\mathrm{T}=$ core gas temperature at TDC.

Fig. 4 : Pressure history of a non reactive mixture n-pentane $/ \mathrm{N}_{2} / \mathrm{Ar}=0.0256 / 0.2048 / 0.7696$. Symbols are experimental values, curve is the simulation, initial conditions : $\mathrm{p}_{0}=400$ torrs, $\mathrm{T}_{0}=355 \mathrm{~K}$

Fig. 5 : Temperature history for pentane isomers at the same compression temperature.

Table 1 : Autoignition criteria for stoichiometric hydrocarbon/"air" mixtures 


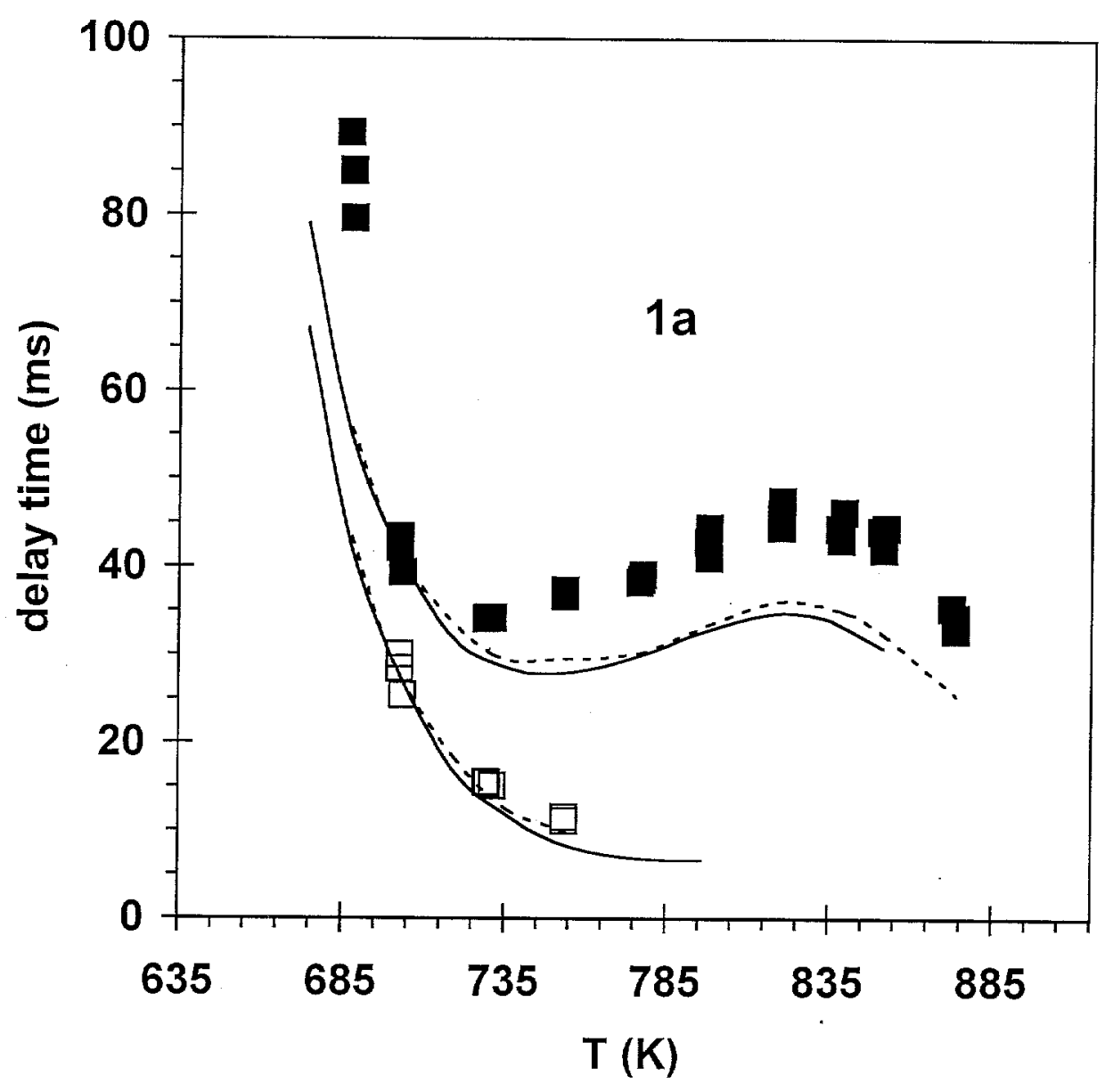




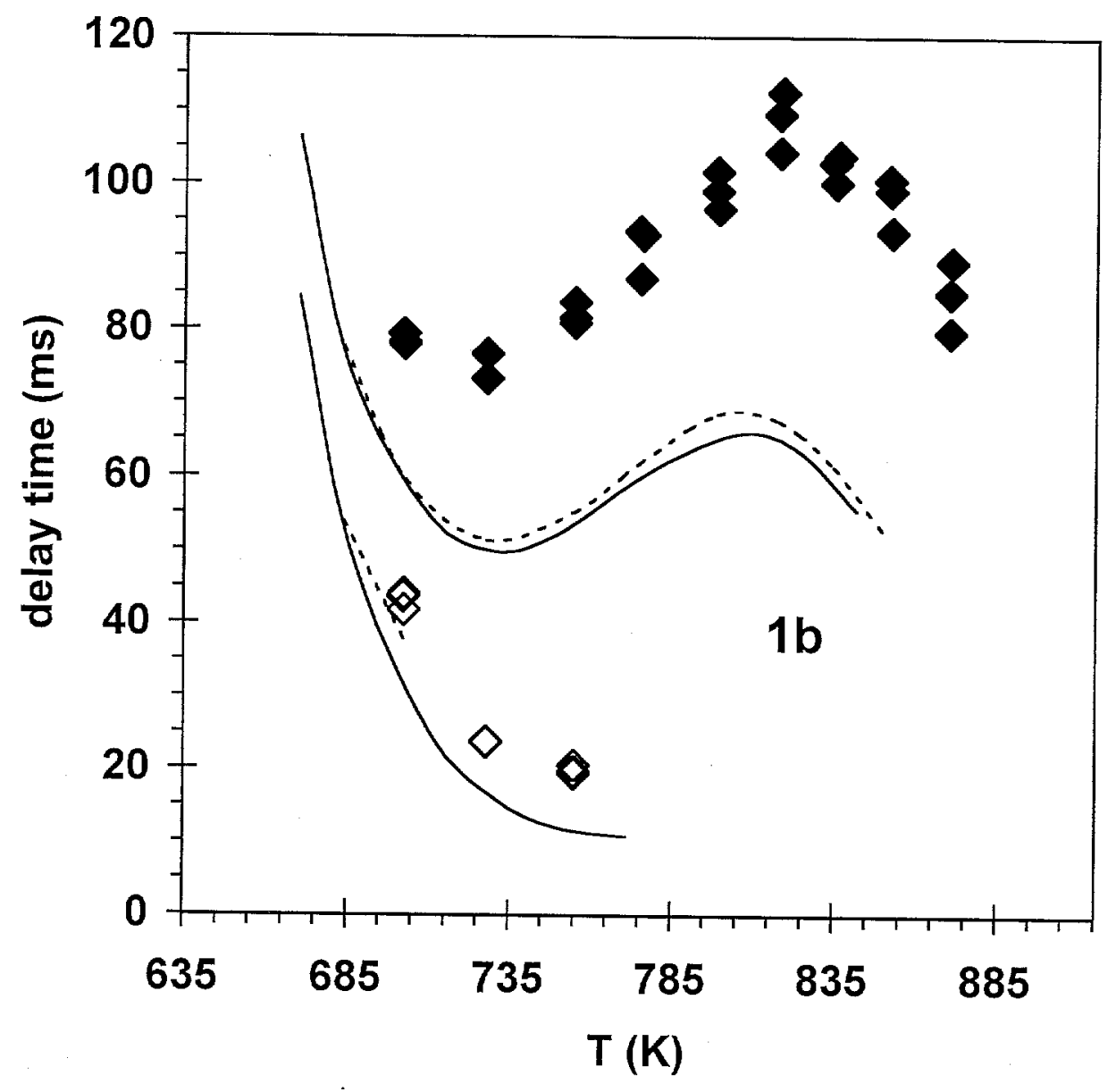




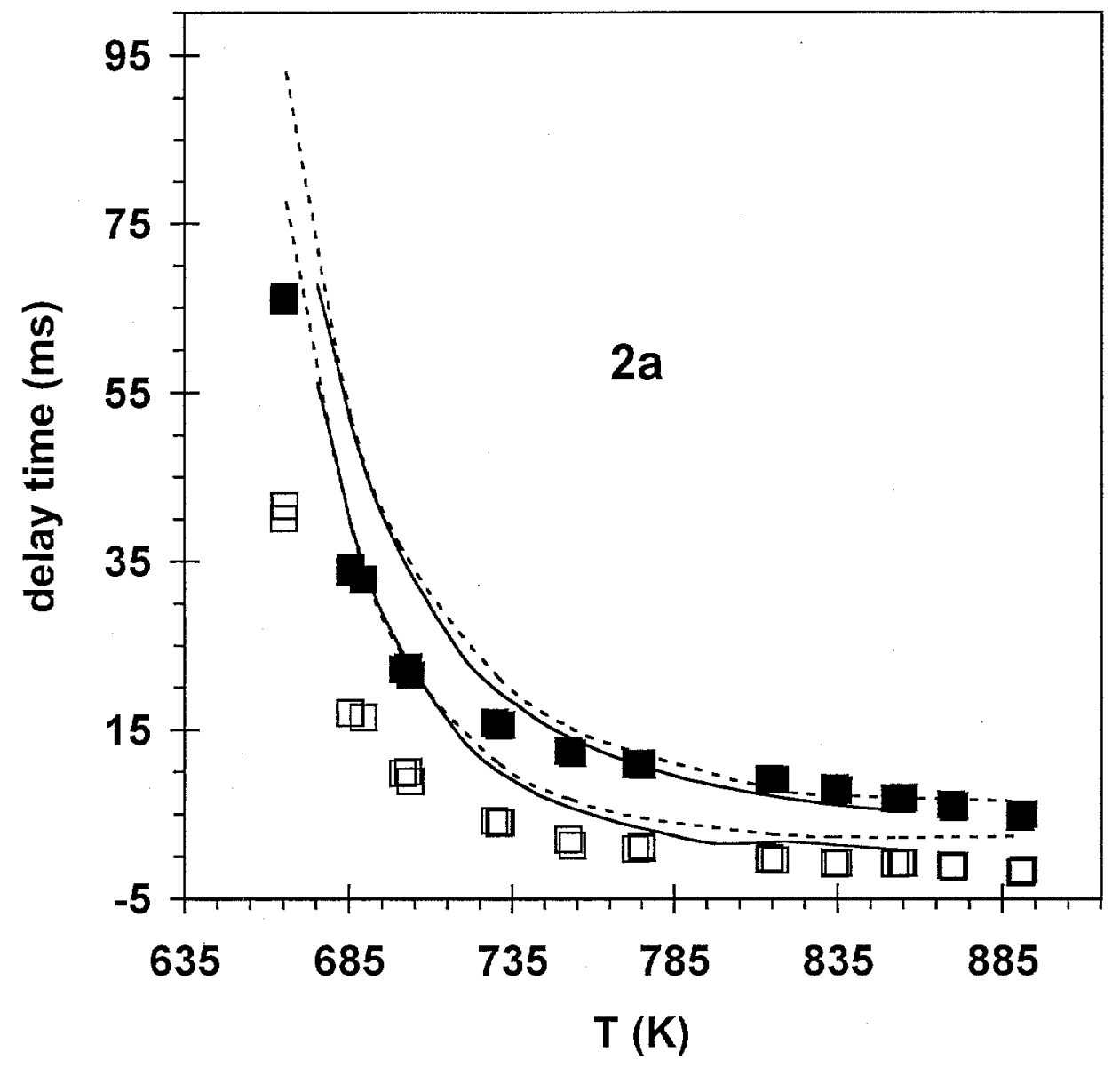




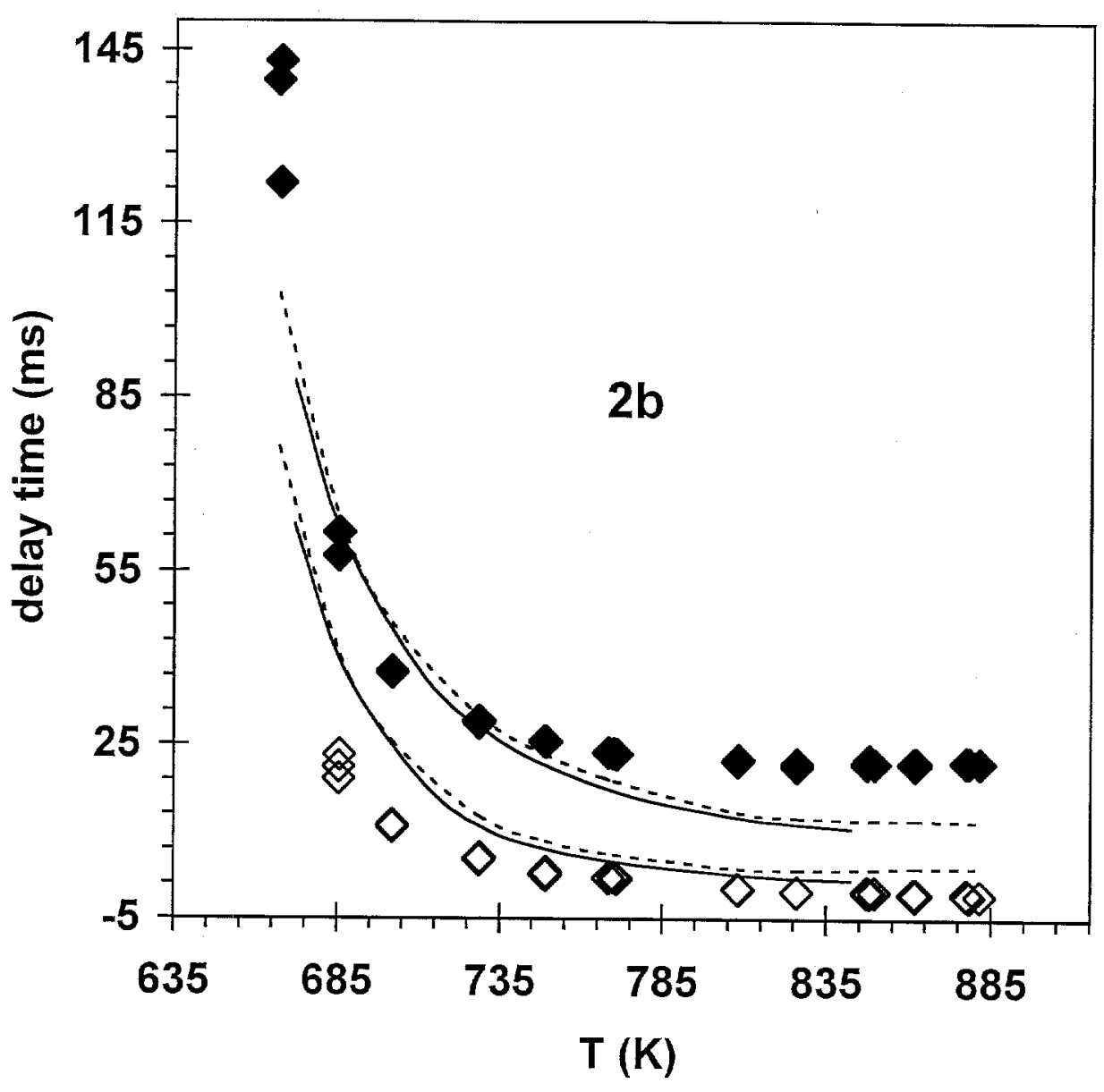




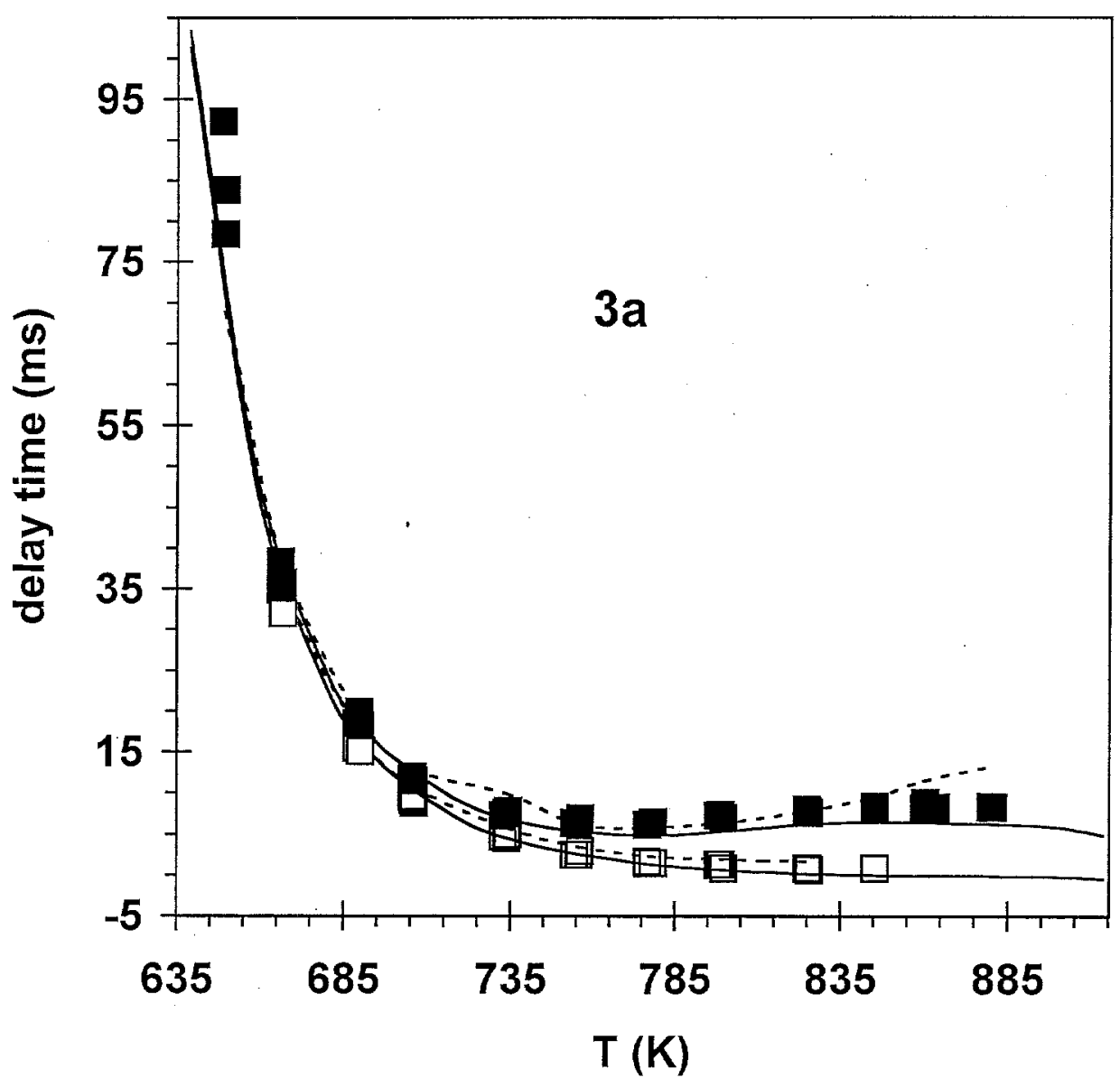




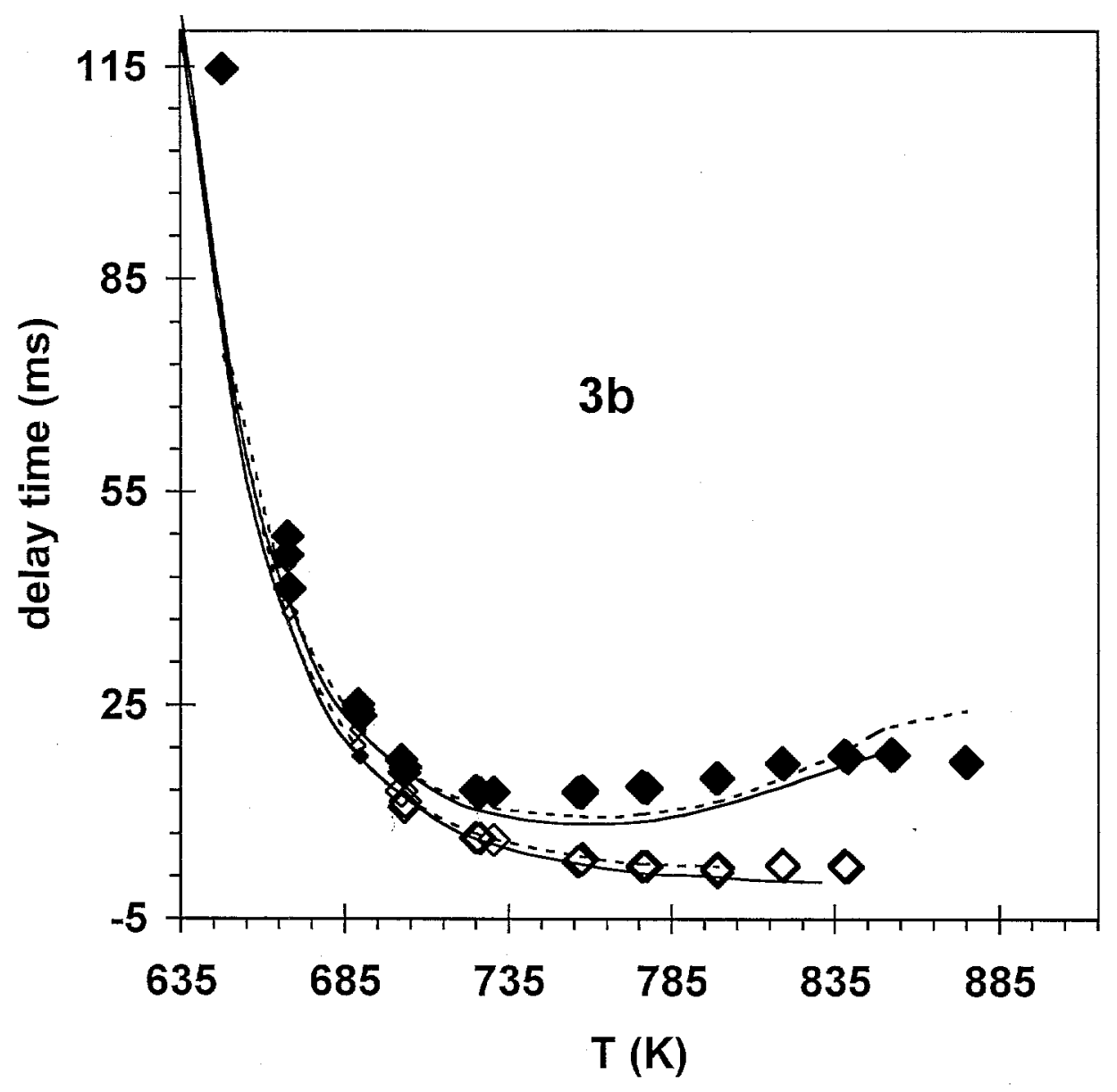




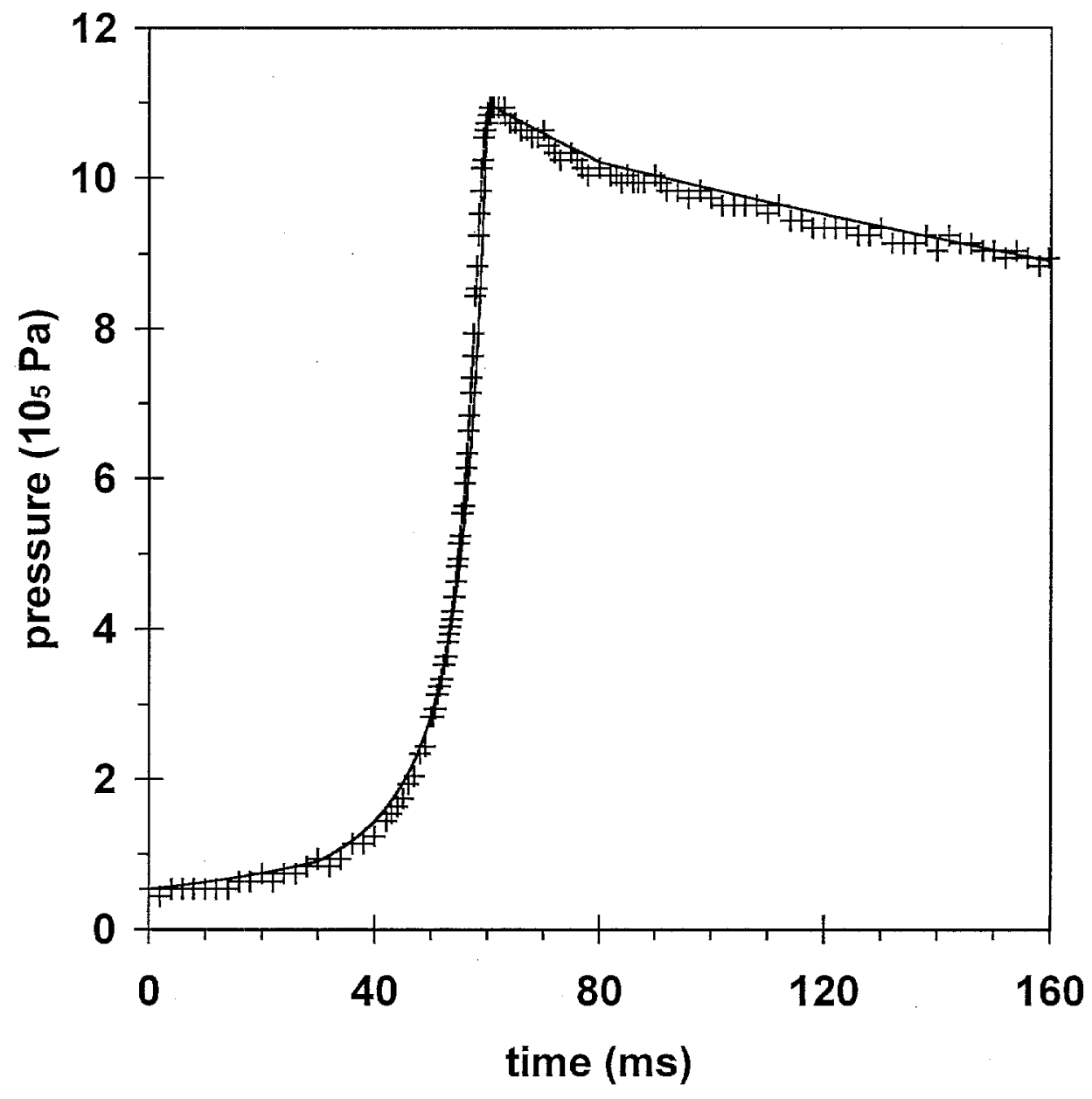

Fig 4 


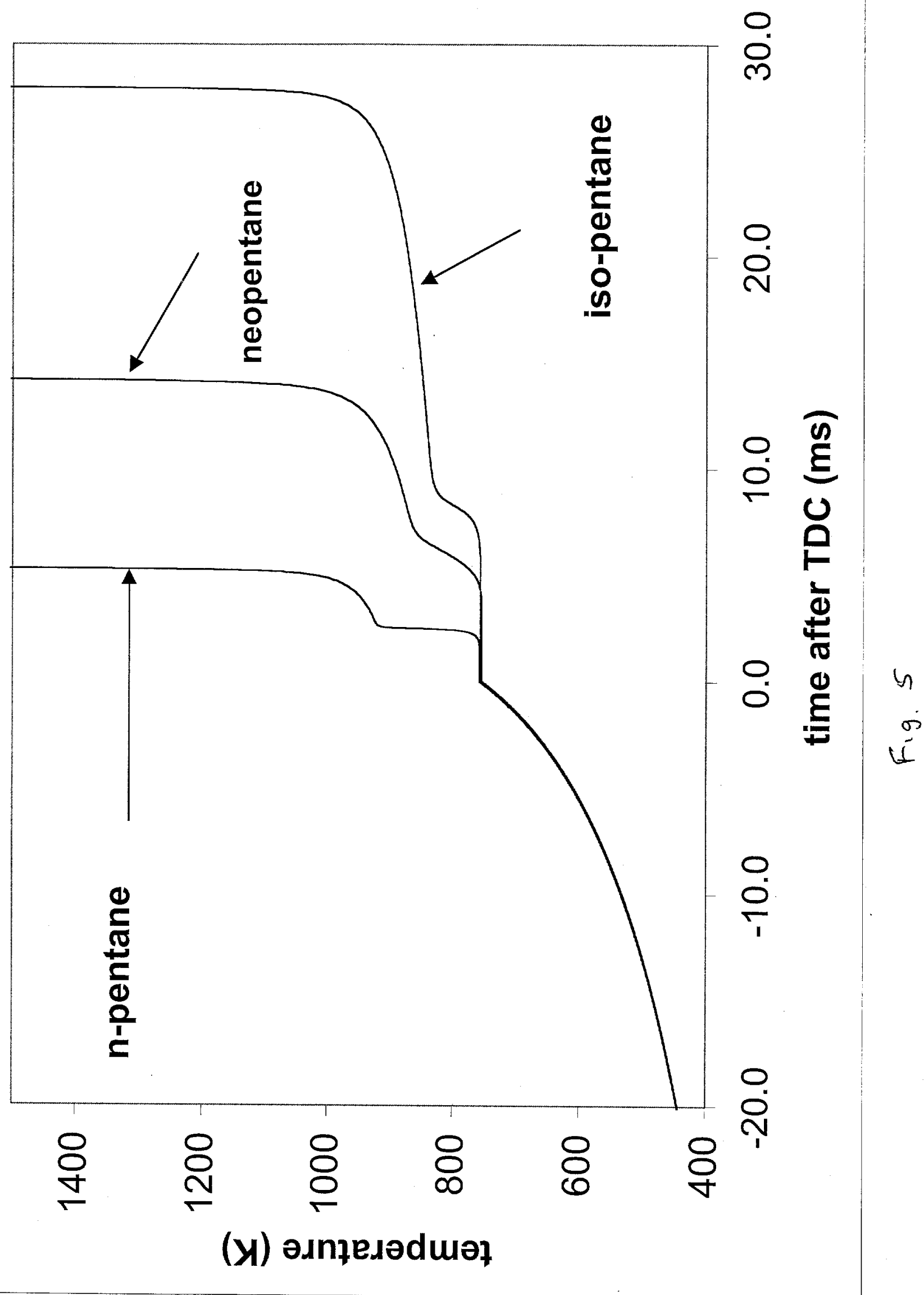




\begin{tabular}{|l|c|c|c|c|c|c|}
\hline hydrocarbon & \multicolumn{2}{|c|}{ isopentane } & \multicolumn{2}{c|}{ neopentane } & \multicolumn{2}{c|}{ n-pentane } \\
\hline $\mathrm{RON}$ & \multicolumn{2}{|c|}{92.3} & \multicolumn{2}{c|}{85.5} & \multicolumn{2}{c|}{61.7} \\
\hline $\mathrm{p}_{0} /$ torr & 300 & 400 & 300 & 400 & 300 & 400 \\
\hline $\mathrm{T}_{1} / \mathrm{K}$ & 700 & 690 & 670 & 665 & 650 & 650 \\
\hline & \multicolumn{2}{|c|}{ NTC zone } & \multicolumn{2}{|c|}{ slowing down zone } & \multicolumn{2}{c|}{ NTC zone } \\
\hline $\mathrm{T}_{\min } / \mathrm{K}$ & 730 & 730 & 770 & 775 & 755 & 755 \\
\hline $\mathrm{T}_{\max } / \mathrm{K}$ & 820 & 820 & 880 & 890 & 850 & 845 \\
\hline $\mathrm{t}_{\min } / \mathrm{ms}$ & 75 & 34 & 21.5 & 5 & 13 & 6 \\
\hline $\mathrm{t}_{\max } / \mathrm{ms}$ & 109 & 46 & 23.5 & 11 & 18 & 8 \\
\hline & \multicolumn{2}{|c|}{$\mathrm{CF}$ zone } & \multicolumn{2}{c|}{ CF zone } & \multicolumn{2}{c|}{ CF zone } \\
\hline $\mathrm{T}_{\text {CFmin }} / \mathrm{K}$ & 700 & 700 & 685 & 665 & 670 & 665 \\
\hline $\mathrm{T}_{\text {CFmax }} / \mathrm{K}$ & 755 & 755 & 880 & 890 & 840 & 845 \\
\hline
\end{tabular}

Table 1 : Autoignition criteria for stoichiometric hydrocarbon/"air" mixtures 